\title{
Method for measurement of the density of thin films of small organic molecules
}

\author{
Hai-Feng Xiang \\ Department of Electrical \& Electronic Engineering, Department of Chemistry and HKU-CAS \\ Joint Laboratory on New Materials, The University of Hong Kong, Pokfulam Road, Hong Kong SAR, China \\ Zong-Xiang Xu, V. A. L. Roy, and Chi-Ming Che \\ Department of Chemistry and HKU-CAS Joint Laboratory on New Materials, The University of Hong Kong, \\ Pokfulam Road, Hong Kong SAR, China \\ P. T. Lai ${ }^{\text {a) }}$ \\ Department of Electrical \& Electronic Engineering, The University of Hong Kong, Pokfulam Road, \\ Hong Kong SAR, China
}

(Received 26 July 2006; accepted 1 February 2007; published online 21 March 2007)

\begin{abstract}
An accurate and sensitive method is reported to measure the thin-film density of vacuum-deposited, small-molecular organic semiconductor materials. A spectrophotometer and surface profiler had been used to determine the mass and thickness of organic thin film, respectively. The calculated density of tris-(8-hydroxyquinolato) aluminum $\left(\mathrm{Alq}_{3}\right)$ thin film was $1.31 \pm 0.01 \mathrm{~g} / \mathrm{cm}^{3}$. Vacuum pressures and thin-film growth rates are found to have less impact on the thin-film density of organic material. However, the thin-film density of organic material strongly depends on its chemical structure and molecular weight. Specifically, the chemical structure determines the density of organic material that affects the molecular volume and intermolecular stacking. () 2007 American Institute of Physics. [DOI: 10.1063/1.2712932]
\end{abstract}

\section{INTRODUCTION}

Density $(\rho)$ is an important parameter of materials and defined as mass $(m)$ per unit volume $(V)$. In order to measure the density, the volume of the material has to be homogenous. Therefore, it is easy to measure the density of homogenous materials such as metals, gases, and liquids, and their densities are available in the literature. However, most of the small-molecular organic materials are in powder at room temperature, which is not homogenous in volume. The traditional way to determine the density of organic materials is to grow a single crystal of the particular material and measure its density by x-ray diffraction. A potential problem could be, through this method, several values of density corresponding to different crystal isostructures depending on the conditions of crystal growth. This problem can be solved by the growth of uniform organic thin films using thermal evaporation under high vacuum. It is obvious that the calculated density from a single crystal varies from the thin film of the same material due to their different molecular arrangements.

Since the 1980s, high-vacuum technology has been facilitating the realization of organic electronic devices, ${ }^{1}$ such as organic light-emitting devices (OLEDs), ${ }^{2-6}$ organic photovoltaic (PV) cells, ${ }^{7-10}$ organic lasers, ${ }^{11,12}$ and organic thinfilm transistors (OTFTs). ${ }^{13-16}$ During the growth of vacuumdeposited organic films, the film thickness and growth rate are detected by the crystal thickness monitor. However, density is one of the parameters that determines the thickness

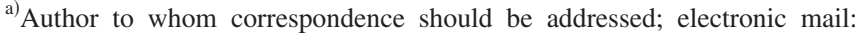
laip@eee.hku.hk
}

and growth rate of the organic material. In addition, to improve device performance, doping technology has been widely adopted in OLEDs ${ }^{17,18}$ and organic PV cells. ${ }^{19,20}$ In this case, the densities of both guest and host are required to calculate the correct doping concentration.

This report describes an accurate method to find out the density of organic thin film based on small-molecular organic materials. We used spectrophotometric determination to determine the mass of organic thin film, and surface profiler to detect the film thickness. Then, the density of the film was calculated by

$$
\rho=\frac{m}{V}=\frac{m}{W L T},
$$

where $W$ is the width of the film, $L$ is the length, and $T$ is the thickness. The effects of vacuum pressure and thin-film growth rate on the density were also explored. To the best of our knowledge, this is the first report that has been published to determine the thin-film density of small-molecular organic materials.

\section{EXPERIMENTAL METHODS}

All organic materials (98\%-99\%) and solvents (analytical grade) were purchased from Aldrich. A glass substrate was cleaned by the following method: soaked in a waterbased detergent by sonication for $10 \mathrm{~min}$ at $60{ }^{\circ} \mathrm{C}$; rinsed with de-ionized (DI) water; sonicated in DI water; sonicated in ethanol, toluene, and acetone for $10 \mathrm{~min}$ at $60{ }^{\circ} \mathrm{C}$, respectively, in three cycles; rinsed with DI water; dried with a nitrogen blowgun; heated at $120{ }^{\circ} \mathrm{C}$ for $2 \mathrm{~h}$ in vacuum; 


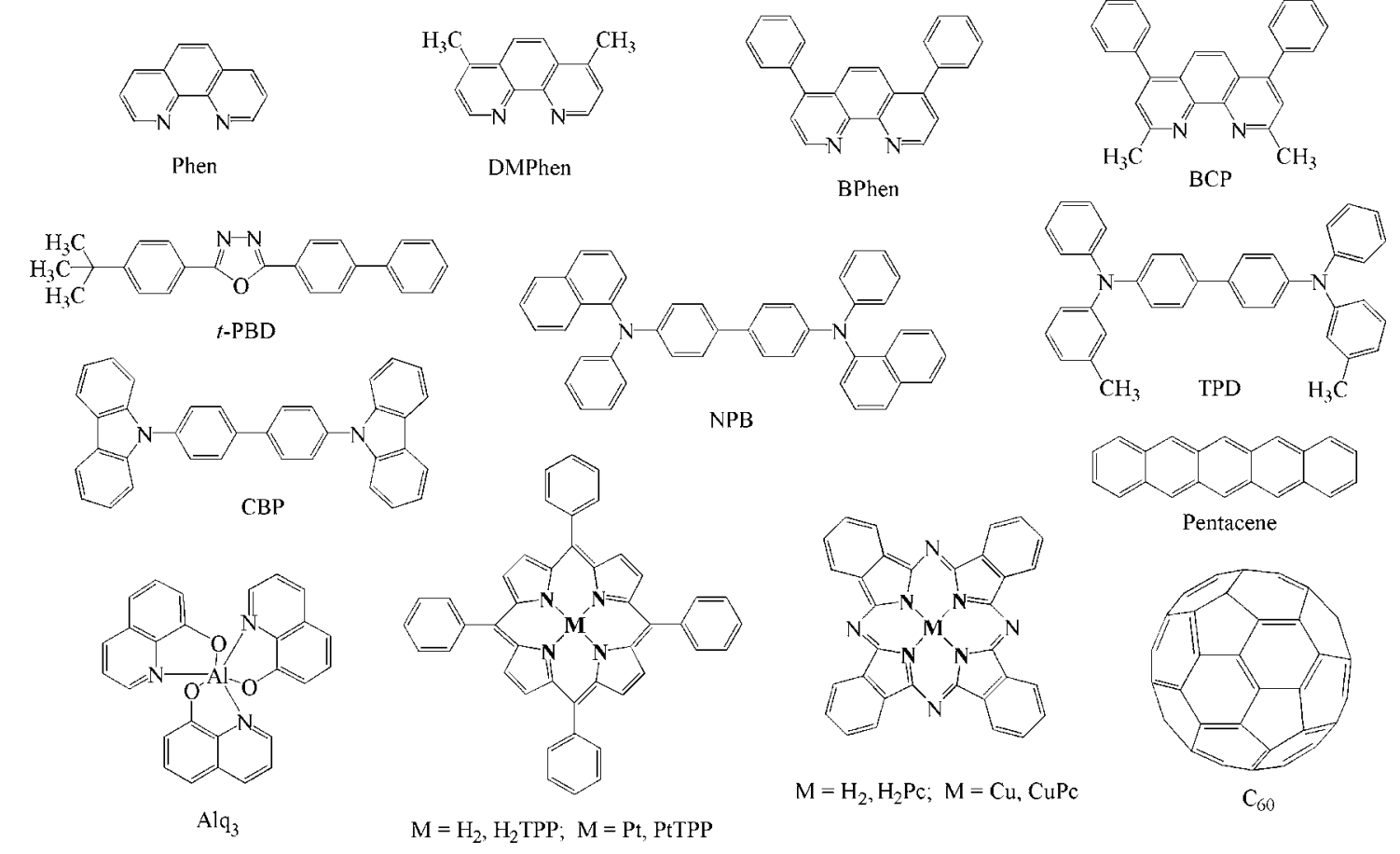

FIG. 1. Chemical structure of organic materials used in this study.

cleaned in UV ozone for $10 \mathrm{~min}$. All organic materials were purified by vacuum sublimation before use. Organic thin films $(100-400 \mathrm{~nm})$ were deposited $(0.2-4.0 \AA / \mathrm{s})$ on a cleaned glass substrate by using a shadow mask in a highvacuum evaporation system (BOC Edwards Auto 306). The deposited organic thin films had a $W$ and $L$ of $2.0 \mathrm{~cm}$. The thickness and growth rate of the thin films were detected by a quartz crystal thickness monitor (BOC Edwards FTM7). The thickness of as-deposited thin films was determined by a Sloan Dektak ${ }^{3}$ ST surface profiler. In order to avoid heat radiation, which affects the amorphous film quality of the organic thin film, the distance between the thermal evaporation crucible and the substrate was kept up to $50 \mathrm{~cm}$.

A standard curve of organic material was plotted between the absorbance at maximum absorption wavelength $\left(\lambda_{\max }\right)$ versus its corresponding concentration in organic solvent. To measure the mass of vacuum-deposited organic thin films, the substrate containing the thin films was dipped into the particular organic solvent $(10-25 \mathrm{ml})$, dissolved by sonication, diluted to appropriate concentration (absorbance in the range of $0.2-0.7)$, and their absorbances were measured by a Perkin-Elmer Lambda 19 UV-visible spectrophotometer. The unknown mass/concentration of an organic material was extracted from its standard curve, and the density was calculated by Eq. (1).

\section{RESULTS AND DISCUSSION}

Figure 1 shows the chemical structures of the organic materials used in this study: 1,10-Phenanthroline (Phen), Bathophenanthroline (BPhen), 4,7-Dimethy-1,10phenanthroline (DMPhen), 2,9-dimethyl-4,7-diphenyl-1,10phenanthroline (BCP), 4, 4' $-N, N^{\prime}$-dicarbazole-biphenyl (CBP), $\quad N, N^{\prime}$-diphenyl- $N, N^{\prime}$-bis (3-methylphenyl)(1,10biphenyl)-4, $4^{\prime}$-diamine (TPD), $N, N^{\prime}$-bis(naphthyl)- $N, N^{\prime}$ - diphenyl-1, 1'-biphenyl-4, 4' -diamine (NPB), tris-(8hydroxyquinolato) aluminum $\left(\mathrm{Alq}_{3}\right)$, 2-(4-biphenyl)-5-(4tert-butylphenyl)-1,3,4-oxadiazole $(t$-PBD), mesotetrakisphenyl porphyrin $\left(\mathrm{H}_{2} \mathrm{TPP}\right)$, platinum(II) mesotetrakisphenyl porphyrin (PtTPP), phthalocyanine $\left(\mathrm{H}_{2} \mathrm{Pc}\right)$, copper(II) phthalocyanine $(\mathrm{CuPc})$, pentacene, and fullerene $\left(\mathrm{C}_{60}\right)$. Most of them are organic semiconductors, widely used in OLEDs, organic PV cells, organic lasers, or OTFTs. All these $\pi$-conjugated organic semiconductors have a strong absorption in the UV-visible region. Therefore, a spectrophotometric determination based on the Beer-Lambert law is a simple, accurate, and sensitive method for finding the concentration of these organic semiconductors in solution.

Spectrophotometric determination is based on the absorption of light by an analyte or sample. In any case, the absorbance $A$ of a sample follows the Beer-Lambert law,

$$
A=\varepsilon l c_{M}=\varepsilon l \frac{m}{M V^{\prime}}=\frac{\varepsilon l}{M} \frac{m}{V^{\prime}}=k c_{m},
$$

where $\varepsilon$ is the molecular extinction coefficient, $c_{M}$ is the molecular concentration, $c_{m}$ is the mass concentration, $M$ is the molecular weight of absorbing specie, $V$, is the volume of the solution, and $l(1.0 \mathrm{~cm})$ is the absorption path length. The absorbance is usually limited to less than 1.0 unless the Beer-Lambert law breaks down due to aggregate formation at high concentration. Since $A$ is proportional to $c_{m}$, it is possible to create a linear plot for absorbance versus concentration when a set of standards of known concentration is measured. This is termed as the standard curve. An equation for this line can be derived and the concentrations of organic semiconductors could be quantitatively determined.

The first efficient low-voltage-driven OLED, demonstrated by Tang, ${ }^{2}$ was based on $\mathrm{Alq}_{3}$. Since then, $\mathrm{Alq}_{3}$ has been widely used as electron-transporting material, green 


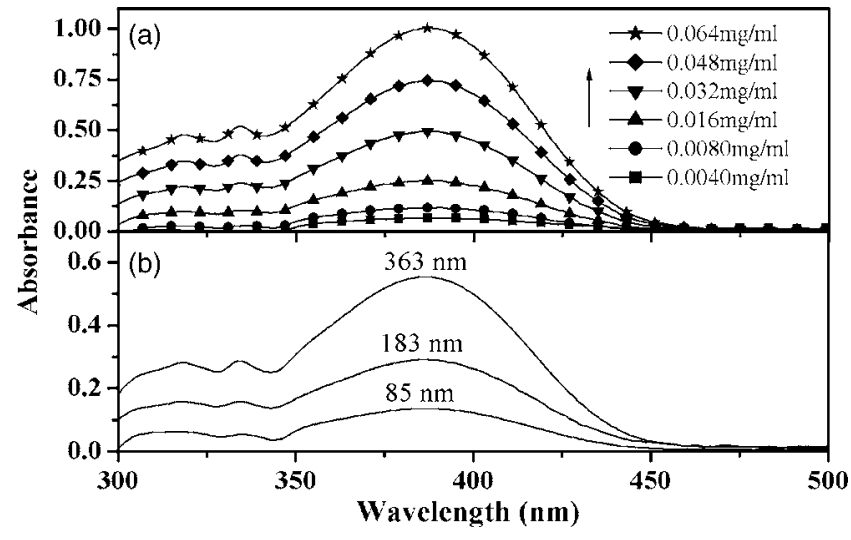

FIG. 2. (a) UV-visible absorption spectrum of $\mathrm{Alq}_{3}$ in $\mathrm{CHCl}_{3}$; (b) UVvisible absorption spectrum of vacuum-deposited $\mathrm{Alq}_{3}$ thin films with three different thicknesses dissolved in $\mathrm{CHCl}_{3}$.

fluorescent emitter, and host material for various dyes to tune the emission color from green to red. ${ }^{17,18}$ Due to its thermal and morphological stabilities, it is feasible to form a goodquality thin film by vacuum deposition. ${ }^{21}$ Hence, we use $\mathrm{Alq}_{3}$ as an example to explain the method for obtaining the thin-film density. In addition, the effects of vacuum pressure and thin-film growth rate on the thin-film density have been explained here.

Figure 2(a) illustrates the absorption spectrum of $\mathrm{Alq}_{3}$ at different concentrations in a solution of $\mathrm{CHCl}_{3}$. The absorbance $\left(\lambda_{\max }=387 \mathrm{~nm}\right)$ of $\mathrm{Alq}_{3}$ was found to be proportional to its concentration. The standard curve for $\mathrm{Alq}_{3}$ exhibited in Fig. 3 shows a good linearity with a correlation coefficient $(R)$ of 0.9999 . Figure 2(b) depicts absorbance at $\lambda_{\max }$ of solutions, which were obtained by diluting vacuumdeposited $\mathrm{Alq}_{3}$ thin films having thicknesses of 85, 183, and $363 \mathrm{~nm}$ deposited at a constant growth rate of $1.0 \AA / \mathrm{s}$ at $1.0 \times 10^{-6}$ Torr. The calculated density for the 85-, 183-, and $363-\mathrm{nm} \mathrm{Alq}_{3}$ films is $1.31,1.32$, and $1.29 \mathrm{~g} / \mathrm{cm}^{3}$, respectively, revealing high reproducibility and accuracy for this determination.

Figure 4 shows the surface-scanning profiles of four 200-nm $\mathrm{Alq}_{3}$ thin films, which were grown at $1.0 \AA$ /s under different vacuum pressures of $5.0 \times 10^{-5}, 1.0 \times 10^{-5}, 3.0$

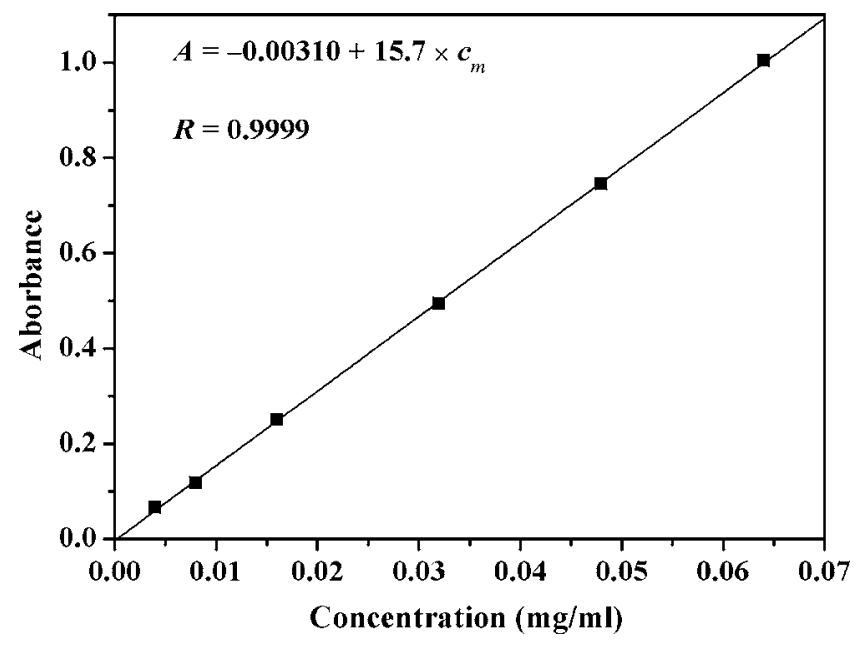

FIG. 3. Standard curve of $\mathrm{Alq}_{3}$ in $\mathrm{CHCl}_{3}$.

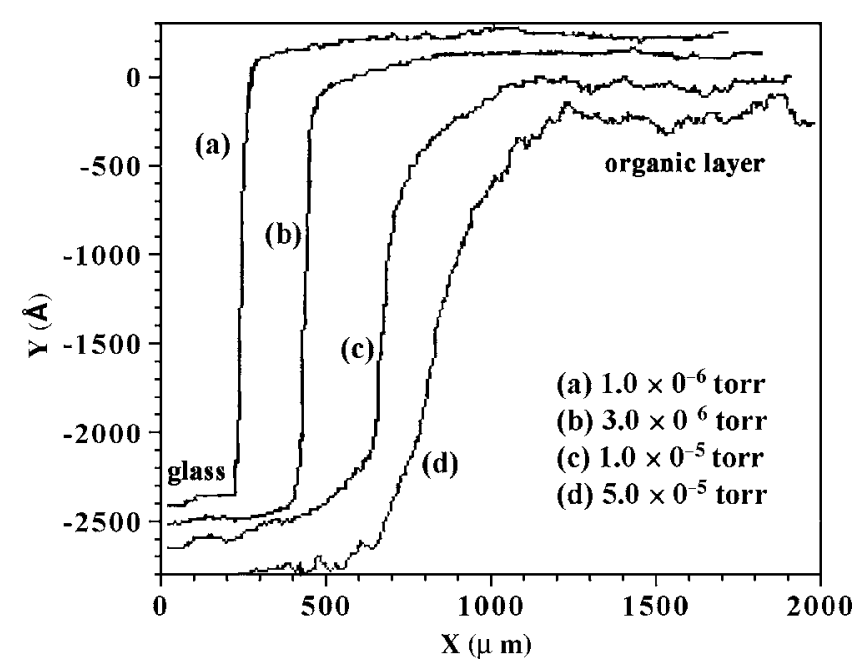

FIG. 4. Surface scanning profile of four $\sim 200$-nm-thick $\mathrm{Alq}_{3}$ thin films with a growth rate of $1.0 \AA / \mathrm{s}$ under different vacuum pressures.

$\times 10^{-6}$, and $1.0 \times 10^{-6}$ Torr, respectively. It has been observed that the vacuum pressure had a strong impact on the surface and profile quality of the thin films. Smaller roughness and sharper profile are formed under higher vacuum. In contrast, the growth rate $(0.2-4.0 \AA$ /s under a high vacuum of $1.0 \times 10^{-6}$ Torr) had less effect on the surface and profile quality of the thin films. However, the overall impact of vacuum pressure and growth rate was small $(<2 \%)$ on the density of the thin films. This can be explained by two reasons: (1) The step $\left(700 \mu \mathrm{m}\right.$ at $5.0 \times 10^{-5}$ Torr and $100 \mu \mathrm{m}$ at $1.0 \times 10^{-6}$ Torr in Fig. 4) profile is much smaller than the length $(2.0 \mathrm{~cm})$ or width $(2.0 \mathrm{~cm})$ of the thin films. (2) Even though the roughness is slightly larger $(100 \AA$ at 5.0 $\times 10^{-5}$ Torr and $50 \AA$ at $1.0 \times 10^{-6}$ Torr) in comparison with the thickness $(\sim 200 \mathrm{~nm})$ of the thin films, the effect could be reduced by calculating the mean thickness or increasing the thickness during the growth of the thin films.

Here $\mathrm{Alq}_{3}$ was used as an example to discuss the error of measurement. The mass of $\mathrm{Alq}_{3}$ thin film can be calculated from its standard curve,

$$
m=(A-0.00110) \times V,
$$

and then

$$
\rho=\frac{m}{V}=\frac{m}{W L T}=\frac{(A-0.00110) \times V}{W L T} .
$$

Therefore, the quantitative uncertainty $(\sigma)$ of this measurement might be contributions from uncertainties in the (1) film thickness $\left(\sigma_{T}=0.30 \%\right) ;(2)$ film length $\left(\sigma_{L}=0.29 \%\right)$ and width $\left(\sigma_{W}=0.29 \%\right)$; (3) concentration of the dissolved film in the liquid, which is calculated from its absorbance $\left(\sigma_{A}\right.$ $=0.19 \%)$; (4) volume of the liquid $\left(\sigma_{V}=0.17 \%\right)$; and (5) standard curve $\left(\sigma_{\text {standard curve }}=0.42 \%\right)$. So the calculated $\sigma$ and density of $\mathrm{Alq}_{3}$ thin film was found to be $0.71 \%$ and $1.31 \pm 0.01 \mathrm{~g} / \mathrm{cm}^{3}$, respectively.

The method described here is a simple and sensitive way for achieving thin-film density. However, it is not suitable for some of the organic materials, because this method requires thermal and morphological stabilities to form good-quality thin films by vacuum deposition, reasonable solubility in or- 
TABLE I. Density of 200-nm-thick organic materials $\left(0.5 \pm 1.0 \AA / \mathrm{s}\right.$ at $1.0 \times 10^{-6}$ Torr $)$.

\begin{tabular}{|c|c|c|c|c|c|c|c|}
\hline & Solvent & $\begin{array}{l}\lambda_{\max } \\
(\mathrm{nm})\end{array}$ & Standard curve & $R$ & $\begin{array}{l}\text { Molecular } \\
\text { weight }\end{array}$ & $\begin{array}{c}\rho^{\mathrm{c}} \\
\left(\mathrm{g} / \mathrm{cm}^{3}\right)\end{array}$ & $\begin{array}{c}\rho^{\mathrm{d}} \\
\left(\mathrm{g} / \mathrm{cm}^{3}\right)\end{array}$ \\
\hline BPhen & $\mathrm{CHCl}_{3}$ & 275 & $A=0.00110+117 \times c_{m}{ }^{b}$ & 0.9999 & 332.41 & $1.22 \pm 0.01$ & \\
\hline $\mathrm{BCP}$ & $\mathrm{CHCl}_{3}$ & 281 & $A=0.00125+111 \times c_{m}$ & 0.9999 & 360.45 & $1.12 \pm 0.01$ & \\
\hline $\mathrm{Alq}_{3}$ & $\mathrm{CHCl}_{3}$ & 387 & $A=0.00310+15.7 \times c_{m}$ & 0.9999 & 459.43 & $1.31 \pm 0.01$ & $1.37^{\mathrm{e}}$ \\
\hline $\mathrm{CBP}$ & $\mathrm{CHCl}_{3}$ & 319 & $A=0.00117+60.6 \times c_{m}$ & 0.9994 & 484.59 & $1.18 \pm 0.01$ & \\
\hline TPD & $\mathrm{CHCl}_{3}$ & 353 & $A=0.00200+70.8 \times c_{m}$ & 0.9999 & 516.67 & $1.08 \pm 0.01$ & $1.19^{\mathrm{f}}$ \\
\hline $\mathrm{CuPc}$ & $\mathrm{PhCl}_{2}{ }^{\mathrm{a}}$ & 675 & $A=0.00565+18.1 \times c_{m}$ & 0.9980 & 576.07 & $1.54 \pm 0.02$ & $1.64^{\mathrm{g}}$ \\
\hline NPB & $\mathrm{CHCl}_{3}$ & 341 & $A=0.00865+66.4 \times c_{m}$ & 0.9999 & 588.74 & $1.19 \pm 0.01$ & \\
\hline $\mathrm{H}_{2} \mathrm{TPP}$ & $\mathrm{CHCl}_{3}$ & 418 & $A=0.00406+714 \times c_{m}$ & 0.9988 & 614.74 & $1.34 \pm 0.01$ & $1.27^{\mathrm{h}}$ \\
\hline $\mathrm{C}_{60}$ & $\mathrm{PhCl}_{2}$ & 333 & $A=0.00576+68.9 \times c_{m}$ & 0.9986 & 720.66 & $1.46 \pm 0.02$ & $1.56^{\mathrm{i}}$ \\
\hline PtTPP & $\mathrm{CHCl}_{3}$ & 402 & $A=0.00742+364 \times c_{m}$ & 0.9998 & 807.8 & $1.67 \pm 0.02$ & $1.69^{\mathrm{j}}$ \\
\hline
\end{tabular}

${ }^{a} \mathrm{PhCl}_{2}=1,2$-Dichlorobenzene.

${ }^{\mathrm{b}} c_{m}$ is the mass concentration in $\mathrm{mg} / \mathrm{ml}$.

${ }^{\mathrm{c}}$ Thin-film density calculated by this study.

${ }^{\mathrm{d}}$ Single-crystal density from other references.

${ }^{\mathrm{e}}$ Reference 29.

${ }^{\mathrm{f}}$ Reference 30.

${ }^{\mathrm{g}}$ Reference 31.

${ }^{\mathrm{h}}$ Reference 32.

${ }^{\mathrm{i}}$ Reference 33.

${ }^{\mathrm{j}}$ Reference 28.

ganic solvent $(>0.01 \mathrm{mg} / \mathrm{ml})$, and strong absorption in the UV-visible region for the materials. As shown in Fig. 1, a series of phenanthrolines, Phen, DMPhen, BPhen, and BCP, with similar chemical structure, were used in this study and this method was found to be suitable only for BPhen and BCP. Phen with a decomposition temperature $\left(T_{d}\right)$ of $106{ }^{\circ} \mathrm{C}$ could not be deposited as a thin film due to its low thermal stability. DMPhen exhibits good thermal stability $\left(T_{d}\right.$ $=305{ }^{\circ} \mathrm{C}$ ) for sublimation, due to recrystallization deposition of uniform thin film not being feasible. The same phenomenon of crystallization was also observed in the thin film of PBD due to its low glass-transition temperature $\left(T_{g}\right)$ of $64{ }^{\circ} \mathrm{C} .{ }^{22,23}$ On the other hand, although both pentacene and $\mathrm{H}_{2} \mathrm{Pc}$ have high thermal and morphological stabilities to form uniform thin films, they do not have enough solubility in organic solvents for performing these measurements.

Density is a parameter of a material, affected by its chemical composition and atomic arrangement. For example, the density of metal is strongly dependent on its atomic weight and radius. The density of metals increases with atomic weight on the whole, but displays a periodic behavior similar to that of atomic radius. Thin-film densities of various organic materials are listed in Table I and plotted in Fig. 5. It can be seen that the thin-film density of organic materials also increases with molecular weight on the whole, similar to that of metals. The bulkiness of organic molecules, like the radius of metal atoms, affects the thin-film density of organic materials. Even though BCP and BPhen (or TPD and NPB) possess similar chemical structures, the density of the former is slightly higher than that of the latter, presumably because the methyl group of the latter disfavors close intermolecular stacking. ${ }^{24,25}$ Moreover, PtTPP and CuPc have higher density due to the close stacking of planar PtTPP and $\mathrm{CuPc}$ molecules with a short intermolecular face-to-face distance. ${ }^{25-28}$ PtTPP, composed of heavy metal Pt(II), has an expectedly higher density than the metal-free $\mathrm{H}_{2}$ TPP. Except for $\mathrm{H}_{2}$ TPP, the calculated densities of the organic thin films are slightly lower than that of organic single crystals (Table I), probably due to the better alignment and packing of molecules in single crystals than those in amorphous films.

\section{CONCLUSION}

In this study, we have demonstrated an accurate and sensitive method to measure the thin-film density of smallmolecular organic materials. Using this method, the calculated $\sigma$ and density of $\mathrm{Alq}_{3}$ thin film was found to be $0.71 \%$ and $1.31 \pm 0.01 \mathrm{~g} / \mathrm{cm}^{3}$, respectively (more detailed information listed in Table I). The results reveal that the thin-film density of these organic materials is not sensitive to vacuum pressure and thin-film growth rate, but strongly depends on their chemical structure and molecular weight, similar to that of metals. Among these organic materials, PtTPP and CuPc have higher density, which can be attributed to the close stacking of essentially planar PtTPP and CuPc molecules

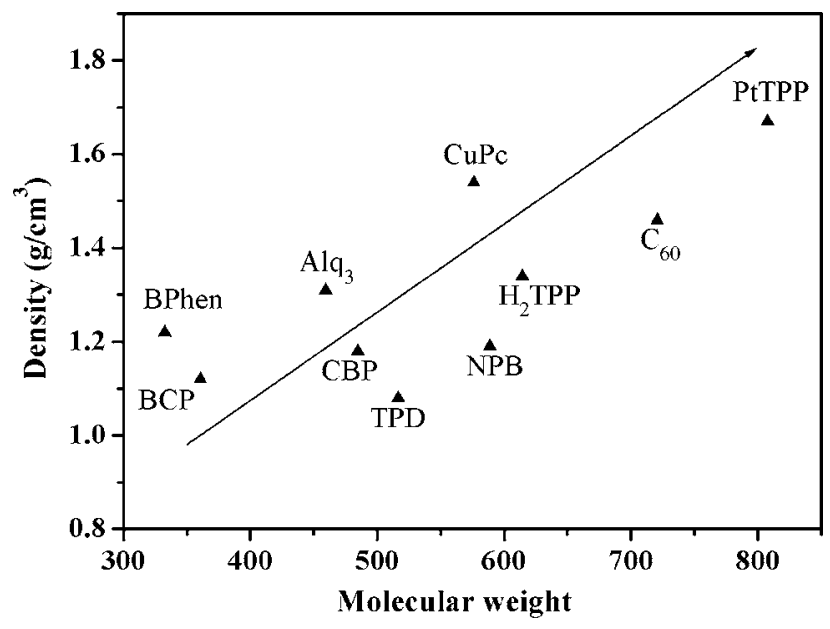

FIG. 5. Density of organic materials vs their molecular weight. 
with a short intermolecular face-to-face distance. Finally, the proposed method could also be adopted to measure the density of polymer thin films, which could be prepared by spin coating or printing.

\section{ACKNOWLEDGMENTS}

This work is supported by the University Development Fund (Nanotechnology Research Institute, Project No. 00600009) of The University of Hong Kong, and RGC of HKSAR, China (Project No. HKU 7158/04E).

${ }^{1}$ S. R. Forrest, Chem. Rev. (Washington, D.C.) 97, 1793 (1997).

${ }^{2}$ C. W. Tang and S. A. VanSlyke, Appl. Phys. Lett. 51, 913 (1987).

${ }^{3}$ Y. Shirota, J. Mater. Chem. 10, 1 (2000).

${ }^{4}$ L. S. Hung and C. H. Chen, Mater. Sci. Eng., R. 39, 143 (2002).

${ }^{5}$ C. T. Chen, Chem. Mater. 16, 4389 (2004).

${ }^{6}$ A. P. Kulkarni, C. J. Tonzola, A. Babel, and S. A. Jenekhe, Chem. Mater. 16, 4556 (2004).

${ }^{7}$ C. W. Tang, Appl. Phys. Lett. 48, 183 (1986).

${ }^{8}$ P. Peumans, A. Yakimov, and S. R. Forrest, J. Appl. Phys. 93, 3693 (2003).

${ }^{9}$ A. Goetzberger, C. Hebling, and H. W. Schock, Mater. Sci. Eng., R. 40, 1 (2003).

${ }^{10}$ K. M. Coakley and M. D. McGehee, Chem. Mater. 16, 4533 (2004).

${ }^{11}$ V. G. Kozlov, V. Bulovic, P. E. Burrows, and S. R. Forrest, Nature 389, 362 (1997)

${ }^{12}$ M. Zavelani-Rossi, G. Lanzani, S. De Silvestri, M. Anni, G. Gigli, R. Cingolani, G. Barbarella, and L. Favaretto, Appl. Phys. Lett. 79, 4082 (2001).

${ }^{13}$ G. Horowitz, Adv. Mater. 10, 365 (1998).

${ }^{14}$ H. E. Katz, Z. Bao, and S. L. Gilat, Acc. Chem. Res. 34, 359 (2001).
${ }^{15}$ C. D. Dimitrakopoulos and D. J. Mascaro, IBM J. Res. Dev. 45, 11 (2001).

${ }^{16}$ M. L. Chabinyc and A. Salleo, Chem. Mater. 16, 4509 (2004).

${ }^{17}$ C. W. Tang, S. A. VanSlyke, and C. H. Chen, J. Appl. Phys. 65, 3610 (1989).

${ }^{18}$ M. A. Baldo, D. F. O'Brien, Y. You, A. Shoustikov, S. Sibley, M. E. Thompson, and S. R. Forrest, Nature 395, 151 (1998).

${ }^{19}$ P. Sullivan, S. Heutz, S. M. Schultes, and T. S. Jones, Appl. Phys. Lett. 84, 1210 (2004)

${ }^{20}$ S. Uchida, J. G. Xue, B. P. Rand, and S. R. Forrest, Appl. Phys. Lett. 84, 4218 (2004).

${ }^{21}$ M. Colle and W. Brutting, Phys. Status Solidi A 201, 1095 (2004).

${ }^{22}$ N. Johansson, J. Salbeck, J. Bauer, F. Weissörtel, P. Bröms, A. Andersson, and W. R. Salaneck, Adv. Mater. 10, 1137 (1998).

${ }^{23}$ F. I. Wu, F. C. Shu, C. H. Chien, and Y. T. Tao, Synth. Met. 148, 133 (2005).

${ }^{24}$ C. M. Che, S. C. Chan, H. F. Xiang, M. C. W. Chan, Y. Liu, and Y. Wang, Chem. Commun. (Cambridge) 2004, 1484.

${ }^{25}$ H. F. Xiang, S. C. Chan, K. K. Y. Wu, C. M. Che, and P. T. Lai, Chem. Commun. (Cambridge) 2005, 1408.

${ }^{26}$ C. J. Brown, J. Chem. Soc. A 1968, 2488.

${ }^{27}$ Z. Bao, A. J. Lovinger, and A. Dodabalapur, Appl. Phys. Lett. 69, 3066 (1996).

${ }^{28}$ A. Hazell, Acta Crystallogr., Sect. C: Cryst. Struct. Commun. 40, 751 (1984).

${ }^{29}$ M. Brinkmann, G. Gadret, M. Muccini, C. Taliani, N. Masciocchi, and A. Sironi, J. Am. Chem. Soc. 122, 5147 (2000).

${ }^{30}$ A. R. Kennedy, W. E. Smith, D. R. Tackley, W. I. F. David, K. Shankland, B. Brown, and S. J. Teat, J. Mater. Chem. 12, 168 (2002).

${ }^{31}$ A. Hoshino, Y. Takenaka, and H. Miyaji, Acta Crystallogr., Sect. B: Struct. Sci. 59, 393 (2003).

${ }^{32}$ S. J. Silvers and A. Tulinsky, J. Am. Chem. Soc. 89, 3331 (1967).

${ }^{33}$ J. M. Hawkins, T. A. Lewis, S. D. Loren, A. Meyer, J. R. Heath, R. J. Saykally, and F. J. Hollander, J. Chem. Soc., Chem. Commun. 1991, 775. 